\title{
ESTILOS
} DOI: https://doi.org/10.11606/issn.1981-1624.v26i1 p68-82.

\section{Artigo \\ Consultas Terapêuticas com pais e filhos: o espaço potencial em reconstrução}

\author{
Leliane Maria Aparecida Gliosce Moreira; Ivonise Fernandes da Motta
}

Resumo. O pedido dos pais por atendimento psicológico do filho tem sido estudado por diversos autores da psicanálise. A ênfase do presente artigo é na teoria do relacionamento paterno-infantil, conforme construída por Winnicott. Segundo o autor, condições favoráveis apresentadas pelo ambiente serão facilitadoras para que a criança possa se desenvolver de acordo com o seu potencial na direção do seu amadurecimento emocional, desde que haja uma sustentação favorável dos pais. O estudo teve objetivo principal verificar se as Consultas Terapêuticas com pais e filhos, desenvolvidas em um Serviço Escola, são um método eficaz para investigar e compreender os mecanismos psíquicos envolvidos na interrupção do percurso de amadurecimento da criança. Nos dois casos analisados, foi possível ter essa compreensão. O método empregado nas intervenções promoveu o resgate da comunicação entre os pais e as crianças, a partir da reinclusão dos pais no papel de sustentação do processo de amadurecimento da criança, cumprindo o complemento da nossa proposta.

Palavras chave: consultas terapêuticas; psicanálise; relação pais e filhos; Winnicott; serviço escola de Psicologia.

\section{Consultas Terapéuticas con padres y hijos: el espacio potencial para la reconstrucción}

Resumen. La solicitud de los padres de atención psicológica para sus hijos ha sido estudiada por varios autores de psicoanálisis. El énfasis de este artículo está en la teoría de la relación paterno-infantil, construida por Winnicott (1979). Según este autor, las condiciones favorables que presenta el entorno facilitarán que el niño se desarrolle de acuerdo con su potencial hacia su madurez emocional, siempre que haya un apoyo favorable de los padres. Este artículo tiene como objetivo presentar consultas terapéuticas con padres e hijos, realizadas en un Servicio de la Escuela de Psicología, como un método eficaz para investigar y comprender los bloqueos que determinaron la suspensión del camino de maduración del niño y la promoción del rescate de la comunicación entre los padres y los hijos. En los dos casos analizados fue posible tener este entendimiento. El método utilizado en las intervenciones promovió el rescate de la comunicación entre padres e hijos, a partir de la reincorporación de los padres en el rol de apoyo al proceso de maduración del niño, cumpliendo el complemento de nuestra propuesta. Palabras clave: consultas terapéuticas; psicoanálisis; relación padres e hijos; Winnicott; servicio escolar de Psicología.

\footnotetext{
* Professora Doutora da Universidade Paulista (UNIP), São Paulo, SP, Brasil. E-mail: lelianemoreira@unip.br

**Professora Livre-Docente no Instituto de Psicologia da Universidade de São Paulo, São Paulo, SP, Brasil. Email: ivonise@usp.br
} 


\title{
Therapeutic Consultations with parents and children: the potential space reconstruction
}

\begin{abstract}
The parents' request for psychological care of the child has been studied by several authors of psychoanalysis. The emphasis of this article is on the paternal-child relationship theory, as constructed by Winnicott (1979). According to this author, favorable conditions presented by the environment will be facilitating so that the child can develop according to his potential in the direction of his emotional maturation provided for a favorable support from the parents. This article aims to present therapeutic consultations with parents and children performed on a Serviço Escola of Psychology as an effective method to investigate and understand the blockages that have determined the suspension of the maturation path of the child and the promotion of the rescue of the communication between the parents and the children. In the two cases analyzed, it was possible to have this understanding. The method used in the interventions promoted the rescue of communication between parents and children, starting from the re-inclusion of parents in the role of supporting the child's maturation process, fulfilling the complement of our proposal.
\end{abstract}

Keywords: therapeutic consultations; psychoanalysis; parents and children relationship; Winnicott; clinical school of Psychology.

\section{Consultations thérapeutiques avec les parents et les enfants: l'espace potentiel pour la reconstruction}

Résumé. La demande des parents pour une prise en charge psychologique de leur enfant a été étudiée par plusieurs auteurs de psychanalyse. Le présent article met l'accent sur la théorie de la relation paternelle-enfant, telle que construite par Winnicott. Selon l'auteur, les conditions favorables présentées par l'environnement permettront à l'enfant de se développer plus facilement en fonction de son potentiel vers sa maturité affective, à condition qu'il y ait un soutien favorable des parents. L'objectif principal de l'étude était de vérifier si les consultations thérapeutiques avec les parents et les enfants, développées dans un service scolaire, sont une méthode efficace pour enquêter et comprendre les mécanismes psychiques impliqués dans l'interruption du cours de maturation de l'enfant. Dans les deux cas analysés, il a été possible d'avoir cette compréhension. La méthode utilisée dans les interventions a favorisé le sauvetage de la communication entre parents et enfants, à partir de la réintégration des parents dans le rôle de soutien au processus de maturation de l'enfant, en remplissant le complément de notre proposition.

Mots-clés: consultations thérapeutiques; psychanalyse; relation parents-enfants; Winnicott; école clinique de psychologie

Serviço Escola de Psicologia atende pais que procuram ajuda especializada diante de situações conflitivas com seus filhos que não compreendem ou sobre as quais não conseguem mais intervir. O psicólogo é, então, chamado para auxiliar pais e filhos a compreender o que está ocorrendo na relação entre eles por meio de intervenções que promovem o resgate do processo de desenvolvimento emocional da criança, ao mesmo tempo em que permitem outra compreensão do seu modo de ser/viver por parte de seus pais.

A ênfase do presente estudo tem por base a teoria do relacionamento paterno-infantil, conforme construída por Winnicott (1975). Para esse autor, as condições favoráveis apresentadas pelo ambiente (pais/família) permitirão que a criança possa amadurecer no tempo e ritmo desejável, ou seja, que ela possa "ser si mesma em um tempo e um e,spaço" (p.40). Se de início a dependência é absoluta, progressivamente a criança ruma para a independência, desde que o ambiente (os pais, a família, os cuidadores, ou seja, quem estiver na função de cuidar) entenda que seu papel permanece, mesmo que modificado, em cada uma das fases do desenvolvimento da criança. Portanto, para Winnicott (1958/2000), é fundamental que haja 
uma provisão ambiental permanente para que o percurso de amadurecimento da criança seja promovido. O sintoma psicológico da criança pode ser compreendido, assim como a comunicação de algo que se passa com ela, em um dado momento do seu processo de amadurecimento emocional, o que implica na necessidade de um espaço e tempo para que isso seja integrado ao seu modo de ser, desde que haja um ambiente favorável como apoio e suporte. Considerando com Winnicott que as diversas tarefas que a tendência inata ao amadurecimento emocional impõe ao ser humano, ao longo da vida, precisam ser sustentadas por um ambiente facilitador, os pais foram incluídos nas Consultas Terapêuticas das crianças em atendimento psicanalítico.

Este estudo teve por objetivo verificar se as Consultas Terapêuticas com pais e filhos desenvolvidas em um Serviço Escola são um método eficaz para investigar e compreender os mecanismos psíquicos envolvidos na interrupção do percurso de amadurecimento da criança. E também verificar se é um método que promove o resgate da comunicação entre os pais e a criança, a partir da reinclusão dos pais no seu papel de sustentação do processo de amadurecimento da criança. Para tanto, foram acompanhadas e analisadas duas consultas terapêuticas de crianças e pais realizadas em um Serviço Escola, buscando determinar se essa modalidade de atendimento clínico favoreceu a retomada do percurso de desenvolvimento da dupla pais/criança.

A proposta das Consultas Terapêuticas com pais e filhos põe em movimento um encontro entre eles, por meio da experiência do brincar em um ambiente especializado, no qual a criança conta como ela está no mundo, e os pais são convidados a resgatar a sua compreensão empática quanto às necessidades da criança, ou seja, a retomar a sua capacidade de abrigar em si mesmos esse momento emocional da criança. O analista está lá para favorecer esse ambiente para ambos, apreendendo que a comunicação significativa da criança advém de sua confiança de que o que está sendo comunicado será compreendido. Esta postura do analista permite que a criança comunique a sua angústia baseando-se no vínculo de confiança e de renovação da esperança de que ela está sendo escutada e compreendida (Motta, 2008).

A Consulta Terapêutica (Winnicott, 1984) é um procedimento que combina diagnóstico e intervenção psicoterápica. Desde o contato inicial, aspectos verbais e não verbais apresentam o motivo da consulta e a intervenção tem início já na primeira consulta, daí o nome de Consulta Terapêutica (Scaduto, Cardoso \& Heck, 2019). Este tipo de consulta, baseada no Self e suas representações que necessitam a presença do outro, segundo a clínica winnicottiana, é "uma nova possibilidade de avaliação, intervenção e ajuda psicológica norteada pela escuta, prática e flexibilidade clínica que advêm da teoria do amadurecimento humano" (Rodrigues \& Mishima-Gomes, 2013, p.92).

Leoncio (2009) relaciona diversos estudos que utilizaram a Consulta Terapêutica como procedimento de intervenção. Além dos clássicos de Winnicott, o autor aponta o método de consultas terapêuticas para crianças por meio do uso de desenhos estórias, desenvolvido por Safra (1984), a intervenção de Catafesta (1992), as consultas terapêuticas com adolescentes indígenas realizadas por Tardivo (2004) e com familiares efetuadas por Leoncio e Tardivo (2006), nas quais um único encontro pode ter sido útil para acolher, acalmar, tranquilizar, esclarecer, orientar e apoiar as famílias. As pesquisas apontadas pelos autores asseguram a efetividade desse tipo de consulta enquanto diagnóstico e intervenção.

Cope (2013) explica que Winnicott se interessou muito pelo brincar como terapia e queria fazer uso das interações verbais e gestuais no ambiente terapêutico. Foi com esse interesse que criou um jogo que chamou de "rabisco", no qual o terapeuta e o paciente desenhavam juntos e 
iam completando os desenhos, um do outro, tendo resultados surpreendentes em algumas interações. O jogo de rabiscos é um instrumento utilizado na consulta terapêutica por Winnicott para chegar a uma compreensão profunda do psiquismo do paciente. Uma maneira valiosa de estabelecer comunicação fácil com a criança a partir do uso de uma técnica simples e flexível, capaz de aproveitar ao máximo o tempo da consulta (Serralha et al., 2016). Nos primeiros contatos com o psicoterapeuta estão presentes na criança grande dose de confiança e esperança de encontrar a compreensão necessária para seu sofrimento e a remoção dos obstáculospara as suas possibilidades de desenvolvimento e maturação. Segundo D. W. Winnicott (1971), nas consultas terapêuticas utilizando o jogo de rabiscos, é recomendável a realização de uma até no máximo três consultas.

A renovação da esperança sustenta o vínculo de confiança e permite a experiência criativa na situação de Consultas Terapêuticas com pais e filhos, especialmente porque a criança e seus pais encontram um ambiente suficientemente bom, isto é, um ambiente que se adapta às suas necessidades. Estando confiantes no ambiente, o espaço potencial pode ser resgatado e logo se pode observar o brincar espontâneo e a comunicação da motivação da angústia. $O$ espaço potencial é a terceira área da experiência de amadurecimento, segundo Winnicott, em que há a sustentação da realidade subjetivamente concebida e da realidade objetivamente percebida e compartilhada. É nessa terceira área que os fenômenos transicionais se tornam existentes e o seu correlato - o objeto transicional, que, segundo Dias (2003), é o símbolo ao mesmo tempo da separação entre a mãe e o bebê, e da união com o que está separado. O espaço parece que foi criado dentro dessa triangularidade: pai, mãe e criança, permitindo diferenciar o símbolo, simbolizando e sujeito interpretador, e deixando-os sentir-se vivos e não seres reativos, como afirma Serralha (2019). A intervenção, portanto, é bem simples: fornecer um ambiente confiável para os pais e para a criança, o que permite o estabelecimento do brincar conjunto. É aí que acontece a escuta clínica: na experiência compartilhada do brincar, em que o "indivíduo pode reunir-se e existir como unidade, não como defesa contra a ansiedade, mas como expressão do EU SOU, eu estou vivo, eu sou eu mesmo" (Winnicott, 1975, p. 83).

\section{Método}

O método da pesquisa foi estudo de caso, com abordagem qualitativa na análise dos dados. Os dois casos clínicos aqui apresentados, cujos nomes são fictícios para ,o sigilo quanto à identidade dos indivíduos, mostram-nos os sintomas apresentados por duas crianças quando há uma crise em seus recursos defensivos para as angústias vivenciadas, quando elas precisam deixar de ser si mesmas para fazer, reativamente, o que o ambiente - seus pais - demanda que elas sejam. Isso se dá quando o ambiente perde sua condição de suporte e apoio às necessidades da criança em cada um dos momentos do seu amadurecimento emocional. Os participantes foram: uma menina de cinco anos, um menino de sete anos e seus respectivos pais. As Consultas Terapêuticas foram realizadas com as crianças e seus pais, sendo que os pais de cada criança foram incentivados a interagir a partir de sessões lúdicas. A analista observou e participou das interações, uma vez que na Consulta Terapêutica o analista participa ativamente do processo.

As Consultas Terapêuticas com pais e filhos têm sido realizadas em um Serviço Escola, onde são supervisionados os atendimentos psicológicos de orientação psicanalítica. A primeira autora faz atendimento psicológica nesta Clínica, por isso foi o ambiente escolhido para o desenvolvimento deste estudo. Descreveremos como essas Consultas Terapêuticas ocorrem no Serviço Escola. Esse serviço possui respeitabilidade na região em que presta serviços 
psicológicos à comunidade, sendo este um dos fatores da grande procura para atendimento psicológico de crianças e adolescentes inscritos por seus pais ou responsáveis legais. Este foi um dos aspectos que determinaram que o atendimento psicológico em Psicodiagnóstico Interventivo, tal como o preconiza Ancona-Lopez (1995), acontecesse em grupo. Mas o princípio primordial que sustenta essa decisão é o entendimento de que "[o]s projetos, sentimentos, ansiedades e conflitos expressos no grupo produzem movimentos de identificação e diferenciação, através dos quais se delineiam as individualidades dos adultos e das crianças" (Ancona-Lopez, 1995, p. 97).

O atendimento psicológico de orientação psicanalítica realizado em grupo, seja ele composto pelos pais ou composto por crianças ou adolescentes, permite a potencialização de experiências compartilhadas e o estabelecimento de um diálogo entre os participantes de cada grupo, principalmente no grupo de pais, construindo uma compreensão conjunta do fenômeno psicológico - sintoma - que se busca investigar e entender.

Os grupos são formados segundo os critérios de faixa etária e de similaridade entre as queixas dos pais relatadas no ato de inscrição de seus filhos para atendimento psicológico no Serviço Escola. O grupo de crianças é composto por no máximo seis crianças, e no grupo de pais estão incluídos todos os pais dessas crianças. $\mathrm{O}$ atendimento psicológico de orientação psicanalítica acontece em três até dez sessões, dirigido pela supervisora com a participação dos estagiários.

Para a entrevista inicial do atendimento psicológico no Serviço Escola são convocados apenas os pais ou os responsáveis pelas crianças que serão atendidas. A proposta dessa entrevista inicial com os pais é facilitar pelo diálogo a emergência de suas ansiedades e conflitos decorrentes das queixas sobre não saber o que fazer, acolhendo de forma compreensiva as ansiedades persecutórias e depressivas sustentadas pelo sentimento de fracasso em relação ao problema atual da criança, assim como obter informações sobre a dinâmica familiar e os aspectos do desenvolvimento da criança. O foco nesse momento é a compreensão do que está acontecendo com a criança e como os pais se sentem em relação à problemática dela, além de saber como eles a percebem e interagem com ela. Nessa ocasião é comum que se busque uma reflexão junto com os pais relacionando aspectos da realidade vivida pela criança que eles costumeiramente apresentam em seu relato com a queixa que determinou o pedido de ajuda especializada. Isso implica em valorizar o conhecimento dos pais sobre a criança e em considerar que a queixa é a representação dos pais do sintoma da criança, o que indica que há uma construção intersubjetiva, um marco do entrelaçamento entre eles. $\mathrm{O}$ sintoma da criança precisa ser compreendido como uma produção conjunta pais/criança, uma vez que reconhecemos que ela constitui a si mesma em uma relação com um ambiente que proporciona as mais diversas experiências significativas. Muitas vezes, isso permite um alívio das ansiedades apresentadas pelos pais e os leva a contar suas preocupações mais livremente.

$\mathrm{Na}$ entrevista inicial estão presentes todos os pais/responsáveis, todos os estagiários que farão o atendimento e a supervisora de estágio. As entrevistas são conduzidas por vários estagiários em uma mesma sala e a supervisora participa acompanhando as atividades.

Na segunda parte dessa entrevista inicial com os pais, a dupla de estagiários responsável pelo atendimento de uma dada criança se reúne com os pais na mesma sala. Chamamos esse momento de o "tempo do cochicho". Busca-se conversar sobre a história familiar e a compreensão dos pais sobre o que está ocorrendo com a criança, a partir da formulação de "questões que busquem esclarecer ou levar os pais a refletir sobre as informações comunicadas durante a entrevista" (Safra, 2005, p. 38-39). Terminado o "tempo do cochicho", os 
participantes são informados sobre as sessões lúdicas em grupo com as crianças e, se necessário, eles serão convidados a participar de uma Consulta Terapêutica com o seu filho, sendo esclarecidas as suas possíveis dúvidas sobre o processo de atendimento psicológico de orientação psicanalítica que for realizado.

Na primeira sessão lúdica em grupo com as crianças, cada dupla de estagiários convida a criança por qual é responsável para brincar focando na comunicação da angústia e no modo como ela expressa os conflitos originadores do sintoma, buscando-se sempre o acolhimento das necessidades da criança. É claro que isso também implica na participação do estagiário como "colega de folguedo", como facilitador dessa comunicação. A dupla de estagiários é determinada previamente para o atendimento de uma criança, porém, cabe a esta escolher, entre os dois, com quem quer interagir/brincar. Como a supervisão clínica ocorre imediatamente após cada uma das sessões lúdicas com as crianças - momento em que são levantadas as hipóteses, por meio da construção da articulação teórico-clínica, sobre o sintoma da criança e sua correlação com o ambiente e o estado em que ela se encontra em seu processo de amadurecimento - pode-se definir a necessidade de incluir os pais e a criança em Consultas Terapêuticas conjuntas. Os critérios para definir a inclusão nessa modalidade de atendimento estão fundamentados na classificação psicopatológica proposta por Knobel (1977), conforme apresentada por Safra (2005), sobre os fenômenos regressivos da infância, especialmente os "processos regressivos normais" e os "processos regressivos reativos". Utilizamos essa classificação porque ela permite um entendimento do surgimento do sintoma correlacionado às experiências da criança com o seu ambiente, ou seja, compreende que o sintoma da criança está relacionado a algum acontecimento ocorrido em um dado momento de sua vida. $\mathrm{O}$ procedimento das Consultas Terapêuticas com pais e filhos é recomendável e benéfico para aquelas duplas (pais e filho) que podem ser classificadas em uma dessas duas categorias, na medida em que podem evitar que "modos patológicos de resolver o conflito se estruturem" (Safra, 2005, p. 36). Consideram-se como modos patológicos de resolução de conflito aqueles que não permitem a continuidade do processo de amadurecimento da criança e é fundamental que, antes da proposição e da realização das Consultas Terapêuticas com pais e filhos, se observe e se verifique o alcance de adoecimento psíquico na relação pais e filho, tendo como premissa que, segundo Safra (2005), o relacionamento da criança com a própria organização psíquica tende a modificar de acordo com as expectativas dos pais em relação àqueles que se tornaram significativos na vida do indivíduo.

O Jogo de Rabisco não foi a técnica adotada nas Consultas Terapêuticas pelo fato de que quatro atores estavam envolvidos no processo, o que poderia dificultar o desenvolvimento dos desenhos para uma compreensão desejável das interações. Apesar de não ser aplicado o Jogo de Rabisco com pais e filhos, utilizou-se o que foi entendido como sendo o fundamento da proposta de análise de Winnicott: a constituição de um lugar-cuidado como experiência de acolhimento que permite à pessoa humana - pais e filhos - vir a se sentir mais amplamente alojada, de modo a possibilitar comunicações significativas.

Ao brincar a criança comunica experiências pretéritas e atuais concomitantemente, e, se esse for um momento compartilhado pelos pais, a consulta pode vir a se tornar terapêutica também para eles, na medida em que mobiliza a identificação e a empatia dos pais em relação à criança, assim como o reconhecimento do que eles não puderam suportar no momento de crise da criança, levando-os muitas vezes a rever aspectos de suas próprias experiências que podem estar ligados aos seus próprios impedimentos de se manterem capazes de ser pais suficientemente bons. Isso requer um manejo próprio do psicanalista em que ele se coloque 
como um facilitador do diálogo entre a criança e seus pais, com a delicadeza e o suporte do cuidar-curar para que haja integração dos sentimentos agressivos à realidade subjetiva da criança e dos pais, propiciando uma nova experiência de desilusão que seja gradativa, e que não ameace a criatividade.

Concordando com Winnicott (1979) que o ser humano somente se constitui na presença do outro, o enquadre psicanalítico nas Consultas Terapêuticas com pais e filhos busca fornecer as condições para que o acontecer humano possa se dar na relação entre eles. Essa maneira de lidar com espaço e tempo na clínica winnicottiana permite o advento do espaço potencial como campo constitucional do trabalho a ser realizado. O sistema familiar pode propiciar um lugar seguro para as brincadeiras, para a criação de símbolos e de significados que fazem sentido para os pais e para a criança. Este espaço potencial entre os membros da família torna-se terapêutico e introduz elementos enriquecedores para a compreensão da dinâmica desse sistema (Polity, 2002).

Ao longo do processo das Consultas Terapêuticas com pais e filhos, a intervenção somente poderá acontecer se a possibilidade de brincar do paciente (pais e criança) esteja estabelecida na relação entre analista e paciente. Também a transferência é compreendida por esse vértice, ou seja, como uma forma de brincar. Os pais e a criança fazem um movimento em busca do analista, e o analista, por sua vez, deixa-se encontrar através da singularidade e do estilo de ser de cada um deles. $\mathrm{O}$ analista está lá, disponível, para ser usado pelo paciente, na medida em que pode colocar em ação a capacidade de viver no espaço potencial. É importante assinalar que essa possibilidade do analista reedita o gesto que parte da necessidade de vir a ser, de existir do paciente. Isto significa que, desde o primeiro momento de encontro, o analista precisa reconhecer qual é a busca que o paciente realiza, qual é a sua necessidade, e isso implica em poder diagnosticar como se organiza o self da criança e o seu ambiente imediato - seus pais -, a fim de que possa permitir que eles criem a situação clínica segundo as suas necessidades e em um tempo singular. $\mathrm{O}$ campo da experiência compartilhada dos pais com a criança pode retomar o ato criativo do brincar permitindo a integração do sentimento gerador da angústia ao si mesmo da criança, e não mais a manutenção dele como um aspecto isolado e desconexo do Eu Sou (self) (Lescovar, 2004).

\section{Resultados e discussão}

É importante salientar que, ao nos ocuparmos na clínica psicanalítica com crianças e seus pais, é preciso realizar uma avaliação conscienciosa do momento do processo de maturação da criança e da sua interface com o ambiente imediato. Dito de outra forma, a presença dos pais nas Consultas Terapêuticas de seus filhos foi promovida quando havia indicativos da capacidade da criança em ter esperança em um encontro humano que viesse em seu auxílio, e quando os pais poderiam fazer um bom uso do progresso alcançado por ela após a finalização das consultas. Além disso, o manejo e o suporte desenvolvidos são fundamentais para favorecer o momento da comunicação significativa da criança e para sensibilizar e mobilizar novamente os pais em direção à identificação empática com a criança.

Winnicott (1971) propõe uma forma de trabalho clínico psicanalítico em que haja a reconstituição da esperança e da confiança da criança no ambiente e em si própria. Considerando que os seres humanos nos mostram o que são e o que não são em cada um dos momentos de suas vidas, pode-se conceber que os fenômenos humanos, quaisquer que sejam 
eles, não podem ser apreendidos e descritos como se fossem representações absolutas e totais, pois são uma manifestação temporal (em um dado momento) do processo de amadurecimento de um ser humano. Entendemos que essa maneira de pensar o fenômeno humano também transforma o modo como compreendemos o sintoma psicológico, que, a nosso ver, passa a ser visto não como ausência de saúde, mas como um fenômeno humano que indica uma perturbação no processo de amadurecimento que necessita ser comunicada e compreendida para ser integrada, por meio da experiência, ao modo de ser do indivíduo.

\section{O caso da Menina Lúcia}

A menina Lúcia tinha cinco anos quando seus pais a trouxeram para atendimento psicológico no Serviço Escola. Na primeira entrevista, seus pais a descreveram como uma criança "agitada, desconcentrada, hiperativa e manipuladora". Eles também informaram sua preocupação de que seu comportamento a prejudicasse em seu desenvolvimento e em seu desempenho escolar, porque ela "não parava quieta e não se concentrava nos estudos, perguntando e questionando tudo para todos". Segundo eles, ela somente queria brincar e não queria estudar. Outra reclamação era que Lúcia queria saber tudo e dirigia seus questionamentos ininterruptos principalmente aos pais e aos avós, quando estava com eles, mas isso também se repetia na escola com os professores que também reclamavam dessa conduta da menina. Apesar de os pais se mostrarem disponíveis e interessados em todos os momentos da entrevista, demonstrando uma preocupação genuína com a filha, foi possível perceber que o pai estava mais ansioso e perseguido do que a mãe. Enquanto o pai era mais enfático quanto à problemática da criança, como se precisasse nos convencer de que tudo aquilo era real, a mãe parecia apontar que não acreditava que houvesse algo de tão errado com a filha.

Lúcia participou de três sessões lúdicas com outras crianças da mesma faixa etária, com a presença dos demais estagiários responsáveis e da supervisora. Em todos esses atendimentos, a criança mostrou-se desinibida, atenta, falante e criativa. Contudo, havia em alguns momentos uma agitação exacerbada desconectada de uma produção criativa e espontânea, acompanhada de um incremento de atitudes agressivas por parte dela, que parecia indicar a emergência de uma angústia. Esta surgia quando a menina não se sentia confiante em ser reconhecida como si mesma, quando por alguma razão não se sentia ouvida e vista como distinta das outras crianças. Era como se ela perdesse a confiança de ser reconhecida como si mesma e precisasse agir de modo agressivo como uma oposição à ameaça de perda da sua identidade. Mostrava-se, ao mesmo tempo, preocupada com os efeitos dessa ação, e o seu brincar se tornava inibido como se esperasse uma reação de não aceitação e de intolerância do ambiente ao seu impulso destrutivo. Compreendemos que ela estava apresentando uma necessidade de acolhimento e suporte à excitação advinda de impulsos destrutivos - espontâneos e repletos de vivacidade que talvez não tenham sido tolerados pelos pais e por isso não puderam ser experimentados em sua totalidade por ela, gerando um estado de angústia primitiva na qual ela perdia de vista o brincar. Decidiu-se, então, convidar os pais a participar de Consultas Terapêuticas com sua filha.

$\mathrm{Na}$ primeira Consulta Terapêutica com Lúcia, participaram os pais da criança e a supervisora. A dupla de estagiários responsáveis por este atendimento observou a condução da Consulta Terapêutica a partir da sala de espelho. Nesta consulta a menina convidou seus pais para brincar e isso ocorreu de maneira franca e genuína entre Lúcia e sua mãe. O pai manteve- 
se mais como um observador, apesar de ser convidado por Lúcia a brincar. Em um dado momento da consulta, Lúcia se tornou mais agitada e passou a desenhar correntes, laços com nós muito apertados, dizendo que queria fazer algo que pudesse ser usado pelo pai e pela mãe, mas que não encontrava o que servisse para os dois. A profissional disse que nem sempre uma coisa servia para dois e que ela podia fazer algo que ela sentisse que serviria para o pai diferente do que ela sentia que serviria para a mãe. Ela então desenhou e pintou uma pulseira para a mãe e um anel para o pai, que reagiu com contentamento, pela primeira vez, ao receber esse presente de sua filha. O pai expressou, então, sua surpresa ao perceber que sua filha era uma pessoa criativa, que se mantinha atenta e concentrada no que estava realizando, e que manifestava alegria ao ser bem recebida em suas expressões afetivas, podendo estar mais identificado empaticamente com a sua filha.

Essa Consulta Terapêutica entre Lúcia e seus pais permitiu apresentá-la como uma criança que não só observava o mundo, mas que interagia ativamente com ele, o que exigia dos seus pais um modo de relação também ativo e participativo com ela. Nas palavras dela: "Agora vocês já sabem que eu sou uma artista, não é mesmo, papai?". Logo depois que Lúcia disse isso, o pai revelou que ele se irritava com a filha, porque ela se parecia com seu irmão, que também era tão criativo quanto sua filha e, por isso, segundo ele, bem mais amado por sua mãe, e que isso o agredia. Entendemos, então, um dos motivos pelo qual o pai se opunha de forma hostil à Lúcia e não podia se identificar empaticamente com ela, levando-o a tratá-la como fazendo parte de sua realidade subjetiva. Foi possível também apresentar aos pais a compreensão de que a agitação de Lúcia era uma manifestação de sua angústia diante da distância afetiva do pai e da sua não identificação empática à necessidade dela de ser si mesma. O estado de excitação exacerbado era movimento em direção a ser reencontrada e reconhecida pelo pai como uma pessoa distinta e única. A partir dessa compreensão foi proposta uma segunda Consulta Terapêutica com Lúcia e seus pais, na qual foi possível observar, por meio do brincar mútuo, que eles estavam se relacionando de maneira genuína e espontânea, e que isso indicava que os pais e a filha haviam recuperado a capacidade de dar continuidade à vida emocional da relação familiar. Os pais estavam devolvidos à Lúcia e agora eles podiam se conhecer e se relacionar. Houve, então, o encerramento do atendimento psicológico de Lúcia e seus pais no Serviço Escola.

Nas consultas terapêuticas a função é analisar o paciente, juntamente com a intervenção, o que possibilita uma gradual modificação no estado emocional do analisando. Na Clínica Escola em questão é esse o procedimento usual. Os supervisores e estagiários praticam a intervenção já na primeira consulta.

\section{O caso do Menino Antônio}

Antônio tinha sete anos quando seus pais procuraram atendimento psicológico no Serviço Escola. $\mathrm{Na}$ entrevista inicial com seus pais, foi perceptível um alto nível de ansiedade, principalmente da mãe, que dizia que o menino "não fazia lição de casa, não se concentrava nas aulas, não se comportava em locais públicos, gritava quando algo não era realizado do modo como ele queria e era agitado". Ela também relatou que Antônio tinha "voltado a fazer xixi na cama, a usar chupeta e que não conseguia soltar a mamadeira". Enquanto a mãe descrevia a criança, o pai se mantinha calado, aparentemente concordando com ela, chegando a dizer em um dado momento que ela "sabia mais sobre o filho", mas também acrescentou que o menino 
era "bom e meigo". A mãe logo se posicionou dizendo que "isso não era suficiente", porque Antônio era "um problema" e que, apesar de "já terem feito de tudo, não haviam conseguido uma solução para o problema do menino".

No momento em que a mãe estava relatando aspectos relacionados à gestação e ao nascimento de Antônio, ela nos contou que o pai de Antônio não soube da gravidez, na época, porque ela não havia contado para ele, pois haviam terminado o namoro. O pai disse que ficou sabendo do nascimento do filho enquanto estava morando em outro país e que ficou "bastante feliz", apesar de não ter sabido antecipadamente da gravidez, o que parecia deixá-lo um pouco ressentido. Pareceu-nos que a não presença do pai, principalmente durante a gestação e o nascimento de Antônio, pode ter gerado na mãe do menino um incremento do desamparo que toda mãe sente diante do desamparo do próprio bebê. Logo cedo, ela precisou se ocupar das coisas do mundo externo, pois o pai do menino não estava lá para protegê-la e para prover o lar. Apesar de ela ter contado com o apoio de sua família, não havia o reasseguramento necessário do amor do pai da criança.

Nas quatro semanas seguintes, Antônio participou de sessões lúdicas com outras crianças da mesma faixa etária e, inicialmente, se manteve calado, parecendo receoso e tímido. Em um dado momento, ele perguntou se poderia brincar, ao mesmo tempo em que já pegava bonecos de animais (quatro ou cinco) dizendo que eles eram "sua família", e colocando-os bem próximos uns dos outros e dele mesmo. Em todos os atendimentos subsequentes Antônio iniciava o seu brincar com "sua família", ampliando aos poucos o seu contato com as outras crianças. Contudo, ele não se desgrudava da "sua família" e tinha que levá-la quando se dispunha a explorar outros materiais e brinquedos que haviam sido colocados à disposição de todas as crianças, inclusive dele, como se a continuidade dos laços afetivos somente estivesse segura com a presença da "sua família". Ao mesmo tempo, isso apontava que havia uma dificuldade de se separar dela como se algo da confiança básica não tivesse sido estabelecido nos primórdios da relação mãe/bebê. Era como se não houvesse confiança e segurança na continuidade da presença viva e real da mãe, o que o levava a permanecer grudado ao que lhe mantinha vivo e real, por estar angustiado frente à separação da mãe, pois isso parecia implicar em perdê-la definitivamente. A regressão apontava o caminho a ser retomado para a reconquista do processo de amadurecimento, e o uso do objeto transicional - "sua família" - era uma maneira de mostrar que estava confiando na provisão ambiental oferecida naquele momento para dar prosseguimento ao seu amadurecimento. Decidiu-se convidar os pais para participar de Consultas Terapêuticas com seu filho.

Na primeira Consulta Terapêutica com Antônio e seus pais, todos estavam inicialmente retraídos e aparentando não saber o que fazer com os brinquedos. Apesar de Antônio se dirigir aos seus brinquedos prediletos, especialmente à "sua família", ele também não conseguia brincar espontaneamente. Como ele já havia demonstrado interesse no uso da tinta guache foi feito o convite para o uso desse material. Ele aceitou e logo começou a misturar as tintas no papel, para, segundo ele, descobrir o resultado da mistura das cores, o que foi compreendido como uma maneira de experimentar o mundo e a capacidade do ambiente para suportar a sua "bagunça e sujeira", como ele mesmo se referia ao seu jogo com as tintas. A mãe mostrou-se bastante incomodada e logo começou a dizer que ele não poderia gastar tudo de uma vez e que deveria fazer um desenho. O pai, por sua vez, pegou um pincel e um papel, e começou a usar algumas tintas para desenhar um carro e pintá-lo de forma bem colorida. Percebendo que Antônio e o pai estavam acessíveis um ao outro e que o brincar deles os aproximava, a analista convidou a mãe para brincar. No entanto, o brincar dela foi realizado de forma automática, 
racional, quase mecânica. Muitas vezes ela dirigia seu olhar para Antônio e seu pai, como se quisesse estar brincando com eles, que, nesse momento, já estavam dando gargalhadas e pareciam bem animados com a brincadeira que estavam realizando. Em um dado momento, a mãe de Antônio perguntou por que ela não conseguia brincar como eles. Esse era um momento significativo, promovido pela experiência daquela modalidade de consulta terapêutica, na qual ela estava em contato com algo profundo - uma primeira pergunta sobre si mesma. A analista respondeu que brincar era algo que estava nela e que ela poderia usar isso. A mãe ficou ensimesmada por um tempo, e perguntou depois para Antônio se ela podia brincar com eles. Pareceu que ela pôde se aproximar da criança. Antônio inicialmente ficou tenso com o pedido da mãe, mas a incluiu em seu brincar desde que a analista também estivesse. Ele precisava da presença da analista para auxiliá-lo a estar com sua mãe em um momento de profunda intimidade. Naquele instante, Antônio e o pai já tinham construído uma cidade e estavam fazendo corridas de carrinhos pelas ruas. Antônio, aos poucos, foi ficando mais agitado e passou a fazer colisões entre os carros dizendo que eles não podiam parar porque não tinham mais freios. O pai ficou assustado, mas a mãe ficou bem mais chocada e recuou diante dessa manifestação agressiva da criança. Diante do suporte e apoio da analista, os pais puderam continuar juntos e se mantiveram ali presentes. Logo em seguida, o pai disse para o filho que os carros poderiam ser consertados e que eles poderiam continuar realizando uma corrida pela cidade, e também construir uma estrada. A intervenção do pai estava permeada por um movimento de preocupação e de reparação, voltado à devida proteção da mãe e da relação de Antônio com ela, o que permitiu que o menino pudesse perceber os possíveis danos que sua agressividade poderia causar. Antônio, sentindo-se preocupado, pôde ser capaz de receber os limites firmes colocados pelo pai. Isto quer dizer que o pai estava mobilizado pela consulta terapêutica e pôde reassumir a função paterna esperada pelo filho, o que auxiliou a mãe a se manter presente e próxima do filho, mesmo diante das reações agressivas da criança.

Antônio e seus pais brincaram juntos na segunda consulta terapêutica conjunta e puderam interagir de forma tranquila e espontânea durante um bom tempo. Em certo momento a mãe passou a corrigir Antônio de forma severa e rígida, dizendo-lhe como deveria recortar o papel e colorir a pipa que ele e o pai estavam arquitetando. Antônio ficou bastante irritado e jogou todas as peças para longe dizendo que não queria "fazer mais nada", que ele "não era bom em nada para a mãe" e que "ela sempre criticava tudo que ele fazia". A mãe reagiu se afastando corporalmente, acuada e com medo, expressando constrangimento de ter sido exposta ao ódio do filho. Ela não disse nada e isso foi sentido como algo terrível por Antônio que imediatamente pegou "sua família" e começou a brincar com ela em silêncio. O pai também se calou, mas continuou a fazer a pipa recolhendo os materiais e objetos que o filho havia espalhado pela sala. Diante dessa cena em que havia três pessoas tão próximas e tão distantes ao mesmo tempo e, considerando que o menino pôde manifestar seu ódio pela primeira vez em palavras tão claras, a analista se aproximou de Antônio e acolheu a expressão do conflito do garoto - os seus sentimentos de ódio e amor em relação à mãe -, comunicando sua compreensão de que seus pais estavam ali e que queriam estar com ele nos bons e maus momentos da sua vida. Logo após, os pais se aproximaram e retomaram o contato com o menino. Percebendo que aquele era um encontro significativo no qual estava ocorrendo a "comunicação profunda e silenciosa que a intimidade traz" (Dias, 2003, p. 136), a analista pôde permanecer fora, inteira e viva, sustentando no tempo e no espaço aquilo que eles estavam naturalmente vivenciando. Assim, finalizou-se a segunda Consulta Terapêutica com Antônio e seus pais. O ódio à mãe manifestado em palavras e em ato por Antônio somente foi possível por ele se sentir seguro 
naquele ambiente especializado. O manejo e a conduta da analista nas consultas terapêuticas com Antônio e seus pais estabeleceram um ambiente suficientemente sustentador, o que o levou a sentir confiança e segurança para expressar o que precisava ser tratado entre ele e a mãe. $O$ ato agressivo de Antônio revelou a sua necessidade de diferenciação da mãe e o impedimento dela em suportar. Antônio estava naturalmente caminhando rumo à independência, mas ao mesmo tempo apresentava uma regressão ao estado fusional mãe/bebê, entendida como uma formação reativa que ocasionava o impedimento da mãe em lhe oferecer suporte à separação. O pai, por sua vez, mostrou ter aptidão para assumir o cuidado materno, o que poderia vir a amenizar as falhas ambientais precipitadas pela mãe, e indicava a possibilidade de pôr em movimento o processo de amadurecimento do filho.

Na terceira Consulta Terapêutica com Antônio e seus pais, os pais compartilharam que agora estavam se reconhecendo e se relacionando, o que indicava que haviam resgatado a esperança na capacidade de dar continuidade à vida emocional da relação familiar. Nessa consulta o brincar pôde ocorrer de forma tranquila por parte do pai e de Antônio, e cautelosa por parte da mãe, que, aparentando uma maior esperança e confiança no encontro estabelecido entre eles, pôde dizer que se sentia "assustada e magoada" com os ataques do menino, mas que agora entendia que "nem tudo era possível". O pai, por sua vez, disse que "entendia os medos do filho" e que estava disposto a "ajudá-lo a entender que eles não iriam desaparecer da vida dele". Foi-lhes dito, então, que os medos precisavam ser cuidados para o fortalecimento da confiança na capacidade para cuidar de Antônio, para dar suporte e apoio às angústias do menino diante das dificuldades encontradas por ele no percurso de seu amadurecimento emocional. Os pais puderam compreender o que foi dito e foi perceptível um brincar mais espontâneo entre os três no qual transpareciam confiança e esperança no futuro. Devolvidos, assim, para seu filho, os pais de Antônio foram encaminhados para um processo de orientação de pais concomitante ao processo psicoterápico do menino, ambos de orientação psicanalítica, no Serviço Escola.

As Consultas Terapêuticas com pais e filhos permitem o acontecer de uma nova experiência compartilhada do brincar, em um ambiente especializado, sustentada na confiança e segurança do vínculo, comportando a comunicação de "uma sucessão de ideias, pensamentos, impulsos, sensações sem conexão aparente" (Winnicott, 1971, p. 81) em busca de uma compreensão possível do que emerge em um momento crítico da vida emocional da criança. A partir da brincadeira o paciente pode mostrar sua criatividade e fazer uso da sua personalidade integral. Assim, a brincadeira nas Consultas Terapêuticas faz com que pais e filhos levem elementos de experiências da realidade construída nesse momento. $\mathrm{Na}$ verdade, o brincar conjunto se manifesta como uma oportunidade de enriquecimento e transformação no campo transicional (Rodrigues \& Mishima-Gomes, 2013).

O brincar na criança, além de ser um importante meio de integração e desenvolvimento dos aspectos cognitivos, linguísticos e afetivos, colabora fortemente para o desenvolvimento infantil de forma integral. A brincadeira entre pais e filhos tem o potencial de trabalhar e melhorar os relacionamentos. Petri e Rodrigues (2020) explicam que o comportamento de brincar de pais e filhos está sendo prejudicado pelo uso excessivo da tecnologia. Mesmo fisicamente presentes, é comum que cada membro da família esteja com seu equipamento tecnológico de modo que a interação não se realize. Parece estar havendo negligência do papel dos pais diante do mundo virtual. Mas isso é assunto para novas pesquisas e futuras discussões. 


\section{Considerações finais}

O objetivo principal deste estudo foi o de verificar se as Consultas Terapêuticas com pais e filhos, desenvolvidas em um Serviço Escola, são um método eficaz para investigar e compreender os mecanismos psíquicos envolvidos na interrupção do percurso de amadurecimento da criança. Observamos que sim. Nos dois casos analisados foi possível ter essa compreensão. A experiência compartilhada do brincar promovida pelas Consultas Terapêuticas com pais e filhos aproxima-nos do espaço potencial criativo e facilitador da retomada do processo de amadurecimento da criança. Mas também nos permite compreender a dinâmica psíquica da relação pais/criança, mostrando como o modo de ser da criança atinge essa relação, quais ansiedades emergem e que defesas são usadas. Isto permite delinear a posição do filho na trama familiar, como os pais se relacionam com ele e, principalmente, em que momento eles sentiram necessidade de ajuda profissional, o que é fundamental para conhecer a provisão ambiental que os pais podem proporcionar à criança, a qual, após o atendimento clínico de orientação psicanalítica, precisa retornar para um ambiente familiar empaticamente voltado às suas necessidades.

Ao expressarem seus temores, expectativas e ideais em relação à criança, os pais também apresentam outro aspecto que os levou ao pedido de ajuda profissional: o mal-estar em relação a si mesmos por não se sentirem confiantes na capacidade de abarcar a angústia do filho. E é neste momento que fica evidente a necessidade do acolhimento da angústia dos pais, o que, por sua vez, fortalece a sua colaboração no processo de atendimento psicológico dos seus filhos. Portanto, acolher e dar suporte aos pais para o restabelecimento de suas condições para auxiliar o filho têm se mostrado um modo eficaz. Podemos pensar que tanto os pais como os filhos são resgatados de uma vivência de abandono, de orfandade.

Foi possível verificar que o método empregado nas intervenções promoveu o resgate da comunicação entre os pais e as crianças, a partir da reinclusão dos pais no papel de sustentação do processo de amadurecimento da criança, cumprindo o complemento da nossa proposta. No decorrer das sessões, os pais e as crianças encontraram mecanismos para uma aproximação e interagiram entre si nas brincadeiras. $\mathrm{O}$ valor das Consultas Terapêuticas está na possibilidade de criar um espaço/tempo do "cuidar-curar" dos pais e da criança para que os pais resgatem a confiança em sua capacidade de, ao se deparar com a angústia da criança, manter o "segurar" nesses momentos de crise, e para que a criança, ao se deparar com o suporte dos pais, possa retomar a esperança na continuidade do seu processo de amadurecimento pessoal.

Outros estudos enfocando as Consultas Terapêuticas em Clínicas-Escolas, talvez com um número maior de participantes, comparando resultados em instituições diferentes podem ser desenvolvidos. Tais pesquisas poderiam corrobar os resultados aqui encontrados, ou trazer novas perspectivas do importante papel da formação prática em cursos de Psicologia.

\section{Referências}

Ancona-Lopez, M. (Org.). (1995). Psicodiagnóstico: processo de intervenção. São Paulo, SP: Cortez.

Cope, K. (2013). Becoming animal, becoming others: What we make with art and literature. American, British and Canadian Studies, (20), 121-138. Recuperado de https://doi.org/10.2478/abcsj-2013-0013 
Dias, E. O. (2003). A teoria do amadurecimento de D. W. Winnicott. Rio de Janeiro, RJ: Imago.

Fávero-Nunes, M. Â. (2019). Formação na clínica: uma experiência inicial com crianças e famílias orientada pela Psicanálise. Semina: Ciências Sociais e Humanas, 40(1), 63-76. Recuperado de http://pepsic.bvsalud.org/scielo.php?script=sci_arttext\&pid=S1676$54432019000100005 \& \operatorname{lng}=$ pt\&tlng $=$ pt.

Knobel, M. (1977). Psiquiatria infantil psicodinâmica. Buenos Aires: Paidós.

Leoncio, W. A. H. (2009). Consultas terapêuticas de crianças abrigadas e seus pais: uma investigação dos vínculos familiares. Tese (Doutorado). Instituto de Psicologia, Universidade de São Paulo. https://www.teses.usp.br/teses/disponiveis/47/47133/tde04082009-093017/pt-br.php.

Lescovar, Gabriel Zaia. (2004). As consultas terapêuticas e a psicanálise de D. W. Winnicott. Estudos de Psicologia (Campinas), 21(2), 43-61. https://dx.doi.org/10.1590/S0103166X2004000200004

Motta, I. F. da (2008). O Inconsciente em debate: Winnicott: algumas implicações para a prática psicanalítica. In Hermann, M. C. (Org.), O inconsciente e a clínica psicanalítica (pp. 6177): Universidade Metodista de São Paulo.

Petri, I. S., \& Rodrigues, R. F. L. (2020). Um olhar sobre a importância do brincar e a repercussão do uso da tecnologia nas relações e brincadeiras na infância. Research, Society and Development, 9(9). Recuperado de https://doi.org/10.33448/rsd-v9i9.7368

Rodrigues, Claudia Mazzer, \& Mishima-Gomes, Fernanda Kimie Tavares. (2013). As flores estão brotando: atendimento infantil em consultas terapêuticas. Psicologia Clínica, 25(1), 89-100. https://doi.org/10.1590/S0103-56652013000100006

Scaduto, A. A., Cardoso, L. M., \& Heck, V. S. (2019). Modelos interventivo-terapêuticos em avaliação psicológica: estado da arte no Brasil. Avaliação Psicológica: Interamerican $\begin{array}{lllll}\text { Journal of Psychological } & \text { Assessment, }\end{array}$ https://dialnet.unirioja.es/descarga/articulo/7055701.pdf

Safra, G. (2005). Curando com histórias: A inclusão dos pais na consulta terapêutica da criança. Edições Sobornost.

Serralha, C. A. (2019). O espaço potencial: da origem à evolução. Estilos da Clinica, 24(1), 157-172. https://doi.org/10.11606/issn.1981-1624.v24i1p157-172

Serralha, C. A., Espote, R., Arruda S. A. V., Silva, M. S., \& Silva, T. B. (2016) . Consultas terapêuticas familiares no tratamento do comportamento agressivo em crianças. Interação em Psicologia (Online), 20, 151-159. doi: http://dx.doi.org/10.5380/psi.v20i2.33911

Polity, E. (2002). Algumas considerações sobre o espaço potencial. Psicologia: teoria e prática, 4(1), 21-28. $\quad$ http://pepsic.bvsalud.org/scielo.php?script=sci arttext\&pid=S1516$\underline{36872002000100003 \& \operatorname{lng}=\mathrm{pt} \& \mathrm{t} \operatorname{lng}=\mathrm{pt}}$

Winnicott, D. W. (1975). O brincar e a realidade (J. O. A. Abreu \& V. Nobre, trads.). Rio de Janeiro, RJ: Imago (Trabalho original publicado em 1971).

Winnicott, D. W. (1982). O ambiente e os processos de maturação: estudos sobre a teoria do desenvolvimento emocional. (I. C. S. Ortiz, trad.). Porto Alegre, RS : Artes Médicas. (Trabalho original publicado em 1979).

Winnicott, D. W. (1984). Consultas Terapêuticas em Psiquiatria Infantil. (J. M. X. Cunha, trad). Rio de Janeiro, RJ: Imago. (Trabalho original publicado em 1971). 
Winnicott, D. W. (2000). Da Pediatria à Psicanálise. (D. Bogomotez, trad.). Rio de Janeiro, RJ: Imago. (Trabalho original publicado em 1958).

Revisão gramatical: Alan Osmo

E-mail: alanosmo8@gmail.com

Recebido em março de 2020 - Aceito em março de 2021. 